\title{
Effects of Soil Acidity and Organic Matter by Application of Organic Materials and Soil Mulching with Pine Needles for Soil Surface Management in Blueberry Eco-Friendly Farming
}

\author{
In Ahn, Sam-Hyun Kim*, Woon-Young Maeng, In-Eae Lee, Ki-Woon Chang ${ }^{1}$, and Jong-jin Lee ${ }^{2}$ \\ Korea Eco-Friendly Agromaterials Association, Seoul 137-942, Korea \\ ${ }^{1}$ Chungnam National University, Daejeon 305-335, Korea \\ ${ }^{2}$ Pharmeceuticals Agro Nutriceuticals, Daejeon 305-335, Korea
}

(Received: September 30 2013, Accepted: November 27 2013)

The bluebeny eco-friendly farming requires the soil condition of $\mathrm{pH} 4.2 \sim 5.2$ and high in organic matters for stable growth. Most of soil types of blueberry-growing land in Korea, however, belongs to alkaline soils with low organic matter content. As a result, the eco-friendly blueberry growers use peat moss and sulfur powder heavily to improve the soil condition, but the guideline on the effective use of organic materials was not established yet. Therefore, this sturdy was performed to investigate the effect of increasing soil acidity and organic matters by using organic materials. Among 5 organic materials, the $\mathrm{pH}$ of soil was lowest in degradable sulfur + bentonite ( $\mathrm{pH}$ 4.1) and followed by Peat moss + Chaff + Pine Needlesmixtures(pH 4.5), OrganicAcid +vinegar (pH 4.7), Sulfur powder (pH 4.8), Temperature response Elutioner (pH 5.2). The soil organic matter content were increased in the following order: Peat moss + Chaff + Pine Needlesmixtures $(8.4 \%)$ $>$ degradable sulfur + bentonite $\mathbf{( 7 . 8 \% )}>$ Organic Acid + vinegar (7.2\%) $>$ Sulfur powder $\fallingdotseq$ Temperature response Elutioner (6.3\%). Although different in the degree, all organic materials treated was recognized a good material for improving soil $\mathrm{pH}$ and organic matter content. The plant height and stem diameter of bluebeny were no clear difference among 5 organic materials. Another study was carried out to investigate amending soils with organic matter by soil mulching with pine needles for soil surface management in blueberry organic cultivation. The effect of increasing the soil $\mathrm{pH}$ by pine needle mulching in blueberny eco-friendly farming was recognized in four test fields. Pine needle mulching for soil surface management in blueberry appeared several advantages, such as improving of soil $\mathrm{pH}$ and organic matter content. Therefore, pineneedle mulching in blueberry organic farming is considered as the most efficient means of mulching cultivation for amending soil $\mathrm{pH}$, weed suppression and moisture conservation among mulching materials.

Key words: Blueberries, Eco-friendly farming, Pineneedle mulching, Soil pH, Organic materials

The effects of pineneedle mulching on soil properties of blueberry field.(2012 13)

\begin{tabular}{llccc}
\hline \multirow{2}{*}{ Sampling area } & \multicolumn{1}{c}{$\begin{array}{c}\text { Pine Needles mulching or } \\
\text { non-mulching }\end{array}$} & $\mathrm{pH}(1: 5, \mathrm{w} / \mathrm{w})$ & OM (\%) & moisture $(\%)$ \\
\hline \multirow{2}{*}{ Muju } & Pine Needles mulching & $4.52^{\mathrm{cd}}$ & $4.15^{\mathrm{c}}$ & $60.2^{\mathrm{b}}$ \\
& non-mulching & $4.96^{\mathrm{bc}}$ & $3.87^{\mathrm{c}}$ & $47.6^{\mathrm{de}}$ \\
\hline \multirow{3}{*}{ Oukcheon } & Pine Needles mulching 1 & $5.14^{\mathrm{bc}}$ & $4.79^{\mathrm{c}}$ & $64.6^{\mathrm{a}}$ \\
& Pine Needles mulching 2 & $3.77^{\mathrm{d}}$ & $10.01^{\mathrm{a}}$ & $57.2^{\mathrm{b}}$ \\
& non-mulching & $6.42^{\mathrm{a}}$ & $3.71^{\mathrm{c}}$ & $45.5^{\mathrm{e}}$ \\
\hline \multirow{2}{*}{ Seongnam } & non-mulching 1 & $5.62^{\mathrm{abc}}$ & $8.05^{\mathrm{b}}$ & $49.8^{\mathrm{d}}$ \\
& non-mulching 2 & $6.34^{\mathrm{a}}$ & $3.87^{\mathrm{c}}$ & $33.6^{\mathrm{f}}$ \\
\hline \multirow{2}{*}{ Hwasong } & non-mulching 1 & $4.98^{\mathrm{bc}}$ & $7.50^{\mathrm{b}}$ & $59.0^{\mathrm{b}}$ \\
& non-mulching 2 & $5.75^{\mathrm{ab}}$ & $5.35^{\mathrm{c}}$ & $53.7^{\mathrm{c}}$ \\
\hline
\end{tabular}

*Corresponding author : Phone: +82220583131, Fax: +82220582211, E-mail: shk6179@hanmail.net

${ }^{\S}$ Acknowledgement: This work was carried out with the support of "Cooperative Research Program for Agriculture Science \& Technology Development (Project No. PJ907156)" Rural Development Administration, Republic of Korea. 


\section{Introduction}

블루베리는 항산화 작용에 의한 노화예방 (Su와 Chien, 2007) 및 시력증진 (Schmidt et al, 2004) 등 기능성 부각으 로 수요증가에 따른 농가 소득작목으로 각광받으면서 재배 면적이 해마다 급증해 2011년 1,082 ha에서 2012년에는 전 체 블루베리 재배면적은 $1,700 \mathrm{ha}$ 에 달한 것으로 추정하고 있으며, 이중 친환경인증면적은 전체의 $15 \%$ 정도이다 (한국 블루베리협회, 2012). 블루베리는 산성을 좋아하는 과수로 하이부쉬 블루베리는 토양 $\mathrm{pH}$ 가 4.0 5.0, 래빗아이는 이보 다 범위가 넓어 4.2 5.2에서 잘 자라는데, 적정 산도보다 토양산도가 높을 경우 생육이 부진하다 (Eck et al 1990). 또한 유기물함량이 $40 \mathrm{~g} \mathrm{~kg}-1$ 이상, 모래가 $80 \%$ 이상인 양 질사토에서 잘 자란다 (Korcak, 1989). 그러나 국내 작물 재 배토양은 유기물 함량과 토양 $\mathrm{pH}$ 조건이 블루베리를 재배 하는데 부적합 할 뿐 아니라 (Lee et al., 2010), 토성 역시 양토, 사양토, 그리고 미사질양토가 전체토양의 약 $80 \%$ 를 차지하고 있어 개선할 필요성이 있다 (Kim at al, 2003). 이 와 같은 불리한 토양환경을 개선하기 위하여 블루베리를 심 기 전에 토양의 상태를 점검하는 가장 중요한 요소는 토양 의 $\mathrm{pH}$ 수치와 유기물 함량으로, 친환경 블루베리 재배농가 들은 블루베리 토양산도 교정을 위해 일반적으로 유황가루 를 뿌리고, 피트모스를 이용하여 $\mathrm{pH}$ 를 조절하고 있다. 미국 에서는 래빗아이는 5.3 이상, 하이부시는 5.0 이상일 경우, cottonseed meal, 우드칩을 토양표면에 살포하거나 수용성 황 (90\%)이나 묽게한 산 (酸) 또는 구연산 용액을 점적관수 로 시용하는 방법을 추천하고 있다 (미국 노스캐롤라이나주 2001). 그러나 유황가루 이용은 비용이 저렴하나 토양산도 조정에 많은 시간이 필요하고 산도유지 기간이 짧은 점을 개선하기 위한 산도 조정 기술이 필요하다 (Kwon et al., 2010). 그러므로 토양 산도의 조절은 성공적인 블루베리 재 배를 판가름하는 가장 중요한 요소이며 묘목의 성장 및 품 질에 큰 영향을 미친다. 이에 따라 친환경 블루베리 재배시 $\mathrm{pH}$ 를 손쉽게 교정할 수 있는 효율적인 환경친화적인 자재 를 선발하기 위하여 경기도 화성, 성남 및 충남 예산지역의 노지 및 분 재배 포장에서 기존 유황외 5 종의 유기농자재를 공시하여 비교시험을 실시하였다. 한편 블루베리 친환경재
배시 멀칭을 하지 않고 나지로 방치할 경우 강우에 의한 토 양 침식으로 인해 천근성인 블루베리의 뿌리가 노출되거나 잡초 번무에 의한 양. 수분의 경합, 토양건조로 생육이 불량 해 지는 등의 문제점을 해소하기 위해 지표면을 유기물로 멀칭하는 재배농가가 늘고 있으나 볏짚, 왕겨는 잡초종자 혼입우려와 화재 위험성이 있고, 톱밥은 분해되면서 질소성 분을 흡착하는 성질이 있으며, 파쇄목과 피트모스는 수입에 의존하고 비교적 가격이 비싼 단점이 있어 최근에는 솔잎을 멀칭하는 농가가 늘어 나고 있으나 (Ahn et al., 2012), 그 효과에 대한 직접적인 연구사례가 없어 정확한 시험이 필요 한 실정이다. 따라서 본 연구에서는 블루베리 솔잎멀칭에 의한 $\mathrm{pH}$ 교정 효과 등을 규명하기 위하여 식재 골사이를 친 환경 부직포 피복과 동시, 주변 야산에서 쉽게 채취할 수 있 는 소나무 낙엽인 솔잎을 이용하여 멀칭재배를 한 무주, 옥 천, 논산, 예산지역 5 둔데 친환경 재배포장과 멀칭하지 않 은 무주, 옥천, 논산, 성남, 화성지역 친환경재배 농가포장 과의 $\mathrm{pH}$ 및 유기물함량을 노지 및 하우스포장에서 비교분 석하여 솔잎멀칭의 효과를 조사하였다.

\section{Materials and Methods}

공시 시료 $\mathrm{pH}$ 교정 효과시험은 경기도 화성시 전곡면 소재 호트팜 농장의 친환경 블루베리 노지재배 포장에서 북 부형 하이부시 블루베리 품종인 Duke (V. corymbosum L.) 3 년생을 공시하여 수행하였다. 공시약제로 유황은 유황분 말 $99.9 \%$ 를, 과립유황은 이분해성 유황 $90 \%$ 와 벤토나이트 $10 \%$ 를 합제로 조제하고, 유기산+목초액은 현미식초 (Ch3cooh $30 \%)$ 와 $\mathrm{pH} 3$ 인 참나무 목초액 (70\%)을 합제로 조제하였으 며, 유황 $40 \%$ 함유 온도반응형 용출비료는 미국에서 새로 개발된 수입제품을 공시하였고, 피트모스+왕겨+솔잎은 피 트모스 (입자크기 20 40 mm, pH 3.6 4.4)+ 왕겨 30\%+ 분 해된 솔잎 $30 \%$ 를 퇴비화하여 공시하였다. 처리약량은 시험 지토양의 평균 $\mathrm{pH} 5.8$ 을 4.8로 낮출 경우를 가정하여 유황 과 분해성 과립유황은 1995 Whitworth 등 국내외 선 연구 결과에 의거 $10 \mathrm{a}$ 당 $140 \mathrm{~kg}$, 유기산+목초액은 $270 \mathrm{kl} / 10 \mathrm{a}$, 피 트모스+왕겨+솔잎 혼합제는 $800 \mathrm{~kg} / 10 \mathrm{a}$, 온도반응형 용출 비료는 수입라벨상 사용량인 $80 \mathrm{~kg} / 10 \mathrm{a}$ 을 기준하여 폿트

Table1. Materials used for comection effect of soil pH in bluebeny.

\begin{tabular}{llc}
\hline \multicolumn{1}{c}{ Materials } & \multicolumn{1}{c}{ Active ingredient } & Treatment \\
\hline Sulfur powder & $99.9 \%$ sulfur & $70 \mathrm{~g} / 0.5 \mathrm{~m}^{3}$ \\
Degradable sulfur granules + bentonite & Degradable sulfur granule $90 \%(99.9 \%$ sulfur) + bentonite $10 \%$ & $70 \mathrm{~g} / 0.5 \mathrm{~m}^{3}$ \\
Organic Acid + vinegar & Organic Acid (pH4.5) $30 \%+$ vinegar (pH3) $70 \%$ & $135 \mathrm{ml} / 0.5 \mathrm{~m}^{3}$ \\
Peat moss + Chaff + Pine Needles & Peat moss (40ms ; pH 4.5) $40 \%+$ Chaff (pH 5) 30\% & $400 \mathrm{~g} / 0.5 \mathrm{~m}^{3}$ \\
Control Release Fertilizer (CRF) & + Pine Needles (pH 4) 30\% & $40 \mathrm{~g} / 0.5 \mathrm{~m}^{3}$ \\
\hline
\end{tabular}


$(50 \times 50 \times 50 \mathrm{~cm})$ 면적으로 환산 시용하였다. 관행 재배법에 준하되 각각의 처리는 난괴법 3 반복으로 수행하였다. 공시 약제별 처리내용은 Table 1 과 같다.

생육상황 조사 유기자재 처리 후 블루베리의 생육상 황을 조사하기 위하여 신초경 및 신초장을 조사하였다. 신 초장은 신초줄기의 생장부에서 선단 끝까지의 길이를, 신초 경은 생장부 상단의 두께를 측정하였다.

근권 토양 분석 토양시료 채취방법은 블루베리가 식 재된 표토 $10 \mathrm{~cm}$ 를 제외한 근권토양을 5 군데서 골고루 채취 혼합시료로 하여 토양 $\mathrm{pH}$ 와 유기물 함량 등을 분석 하였다. 토양 분석방법은 농촌진흥청 토양화학분석법에 준하여 $\mathrm{pH}$ 는 초자전극법, 유기물함량은 Tyurin법으로 토양비료 공인 분석기관인 (주)판코리아연구소에서 분석하였다.

솔잎멀칭 효과조사 블루베리 친환경재배시 솔잎멀칭 에 의한 잡초억제 및 보습효과를 규명하기 위하여 전라북도 무주군 안성면 죽천리 1189소재 농가포장 (품종 : 듀크, 스 파르탄 혼재)을 선정 블루베리 솔잎멀칭포장 및 무멀칭 포 장을 비교하였다. $50 \mathrm{~cm} \times 50 \mathrm{~cm}$ 크기로 발취하여 다년생 및 1 년생잡초의 총건물중을 $7.5,8.312$ 회에 걸쳐 방제가를 조사하였다 * 1 -멀칭구의 잡초총건물중/무멀칭구의 총 건 물중) $\times 100$. 한편 블루베리 솔잎멀칭에 의한 $\mathrm{pH}$ 등 근권토
양 환경변화를 비교하기 위하여 노지 친환경재배로 $15 \mathrm{~cm}$ 이상 두께로 솔잎멀칭을 한 옥천소재 베리굳베리 농원 (양 토) 및 황씨농원 (양토) 2 농가포장과 무주 갈마농원 (사양 토) 1 농가포장을 선정조사 하였으며, 무멀칭 친환경 재배포 장은 무주 (사양토) 1 , 옥천 (양토) 1 , 화성 (사양토) 1 , 성남 (식양토) 2 군데 농가포장을 선정조사 하였다. 블루베리 하 우스재배시 솔잎멀칭에 의한 토양 $\mathrm{pH}$ 및 유기물 함량 변화 를 조사하기 위하여 논산 반딧불농원 (양토)과 예산 산막골 농원 (사양토) 2 농가포장을 선정하여 솔잎멀칭토양과 무멀 칭 토양을 선정 동시에 비교분석 하였다.

\section{Results and Discussion}

\section{유기자재 시용에 의한 블루베리토양 $\mathrm{pH}$ 조절효과} 유기자재 시용에 의한 블루베리 재배토양 $\mathrm{pH}$ 를 조절효과 를 보기 위하여 노지재배조건하에서 시험한 결과는 Table 2 와 같으며, 폿트재배 조건하에서 시험한 결과는 Table 3 과 같다. 노지재배포장의 시험전 토양 $\mathrm{pH}$ 는 6.2 이었으나 4 개 월후 교정효과는 이분해성 과립유황 4.1 , 피트모스+왕겨+ 솔잎 4.5 , 유기산+목초액 4.7 , 유황 분말 4.8 , 온도감응형 유황혼합비료 5.2 로 처리구 공히 교정효과가 뚜렷하였다. 1/1250a 폿트시험 에서도 시험전 토양 $\mathrm{pH}$ 가 5.7 이었으나 교정효과는 이분해성 과립유황 4.0 , 유황 분말 4.4 , 피트모 스+왕겨+솔잎 퇴비 및 유기산+목초액이 각각 4.7 , 온도감

Table 2. Changes in soil pH by organic materials (Field test).

\begin{tabular}{|c|c|c|c|}
\hline Materials & $\begin{array}{c}\mathrm{pH} \\
(1: 5)\end{array}$ & $\begin{array}{l}\mathrm{OM} \\
(\%)\end{array}$ & $\begin{array}{c}\text { moisture } \\
(\%)\end{array}$ \\
\hline (Before experiment) & $6.2^{\mathrm{a}}$ & $5.9^{\mathrm{d}}$ & $51.2^{\mathrm{b}}$ \\
\hline Sulfur powder & $4.8^{\mathrm{bc}}$ & $6.3^{\mathrm{d}}$ & $54.5^{\mathrm{ab}}$ \\
\hline Degradable sulfur + bentonite $G$ & $4.1^{\mathrm{d}}$ & $7.8^{\mathrm{b}}$ & $54.0^{\mathrm{ab}}$ \\
\hline Organic Acid + vinegar & $4.7^{\mathrm{bc}}$ & $7.2^{\mathrm{c}}$ & $58.6^{\mathrm{a}}$ \\
\hline Peat moss + Chaff + Pine Needles & $4.5^{\mathrm{c}}$ & $8.4^{\mathrm{a}}$ & $60.4^{\mathrm{a}}$ \\
\hline Temperature response Elutioner & $5.2^{\mathrm{b}}$ & $6.3^{\mathrm{d}}$ & $52.2^{\mathrm{b}}$ \\
\hline Control & $5.9^{\mathrm{a}}$ & $6.1^{\mathrm{d}}$ & $51.0^{\mathrm{b}}$ \\
\hline
\end{tabular}

Table 3. Changes in soil pH by organic materials (Pots test).

\begin{tabular}{|c|c|c|c|}
\hline Materials & $\begin{array}{c}\mathrm{pH} \\
(1: 5)\end{array}$ & $\begin{array}{l}\mathrm{OM} \\
(\%)\end{array}$ & $\begin{array}{c}\text { moisture } \\
(\%)\end{array}$ \\
\hline (Before experiment) & $5.8^{\mathrm{a}}$ & $12.5^{\mathrm{d}}$ & $60.3^{\mathrm{b}}$ \\
\hline Sulfur powder & $4.5^{\mathrm{b}}$ & $13.7^{\mathrm{d}}$ & $62.6^{\mathrm{ab}}$ \\
\hline Degradable sulfur + bentonite $G$ & $4.0^{\mathrm{b}}$ & $16.4^{\mathrm{b}}$ & $60.8^{\mathrm{b}}$ \\
\hline Organic Acid + vinegar & $4.7^{\mathrm{b}}$ & $16.6^{\mathrm{b}}$ & $63.3^{\mathrm{ab}}$ \\
\hline Peat moss + Chaff + Pine Needles & $4.0^{\mathrm{b}}$ & $19.4^{\mathrm{a}}$ & $65.9^{\mathrm{a}}$ \\
\hline Temperature response Elutioner & $5.0^{\mathrm{ab}}$ & $15.1^{\mathrm{c}}$ & $61.2^{\mathrm{b}}$ \\
\hline Control & $5.8^{\mathrm{a}}$ & $13.0^{\mathrm{d}}$ & $59.3^{\mathrm{b}}$ \\
\hline
\end{tabular}


응형 유황혼합비료 5.0 으로 처리구 공히 교정효과가 인정되 었고 노지포장에서의 시험결과와 다소 차이는 있었으나 대 체로 유사한 결과를 나타내었다. 이는 피트모스 단용구와 피트머스 + 솔잎은 5.1로 비슷하고 피트와 톱밥은 5.4 피트 와 왕겨는 5.9 로 나타났으며, 유황을 300 평당 $160 \mathrm{~kg}$ 살포 했을 때 모든 혼합물에서 토양PH가 4.2-4.5정도로 낮아 졌다 는 선 연구사례와 유사한 경향을 보였다 (Lee et al., 2010), 블루베리가 잘 자랄 수 있고 좋은 수확을 올릴 수 있는 적절 한 토양의 산도는 pH 4.2 5.0 이므로 (원예특작과학원 2010) 본 시험에서의 유기투입재 공히 블루베리 토양산도를 교정 할 수 있는 효과적 수단이라고 판단된다.

유기물함량 변화 한편 유기자재 투입에 의한 유기물 함량 변화는 노지포장에서는 시험전 토양은 5.9 이었으나 피트모스+왕겨+솔잎 퇴비가 8.4, 이분해성 과립유황+벤토 나이트가 7.8 , 유기산+목초액 7.2, 온도반응형 유황비료 및 유황분말은 각각 6.3 으로 나타났다. 폿트시험에서는 용토의 유기물함량이 높아 시험전 토양 및 무처리구의 유기물함량 이 각각 12.5 13.0으로 노지포장에 비해 2배이상 높았으며, 대체로 노지포장과 유사한 경향을 보였다. 그 외 노지포장 및 폿트재배포장의 토양수분 분석결과 각 처리별로 51 66\% 범위로서 무처리구와 큰 차이가 없어 보습효과는 인정할 수 없었으나 블루베리 생장 중에 필요한 토양수분 함량은 50 75\% 로 각 처리구 모두 적정수분 범위에 속하였다.

신초생육효과 유기자재 시용에 의한 블루베리 신초생 육효과는 Table 4와 같다. 유기자재별 신초장은 무처리구가 $28.6 \mathrm{~cm}$ 인데 비해 온도반응용출 유황혼합비료가 $57.5 \mathrm{~cm}$ 로 가장 뛰어났으며, 이분해성 과립유황+벤토나이트합제, 피
트모스+왕겨+솔잎 퇴비, 유황분말, 유기산+목초액 순이었 다. 신초경 성장량도 신초장 성장량과 비슷한 경향으로 온 도반응용출 유황혼합비료가 가장 우수하였고 이분해성 과 립유황+벤토나이트합제, 피트모스+왕겨+솔잎 퇴비, 유기 산+목초액, 유황분말 순이었으나 그 차이는 크지 않았다. 이 결과를 분석해 볼 때 온도반응 용출 유황합제는 요산태 질소가 $20 \%$ 정도 함유 되었기 때문으로 판단된다.

솔잎멀칭에 의한 잡초억제 효과 블루베리 솔잎멀칭 에 의한 잡초억제 효과를 조사한 결과는 Table 6 과 같다. 블 루베리 품종에 상관없이 발생초종은 바랭이, 개망초, 쇠비 름, 참비름, 방동산이, 명아주, 쑥, 냉이, 닭의장풀, 개여뀌, 씀바귀, 깨풀, 개여뀌 등이 발생 되었는 바, 바랭이가 가장 우점이었고, 그 다음으로 개망초, 쇠비름, 명아주, 방동산 이가 많이 발생되었으며, 그 밖에 쑥, 닭의장풀, 냉이, 개여 뀌 등이 소량 발생 되었다. 솔잎 멀칭구는 $1.7 / \mathrm{m}^{2}$ 이 발생되 어 무 멀칭구 $85.0 / \mathrm{m}^{2}$ 대비 방제가 $98 \%$ 의 우수한 잡초억제 효과를 나타내었다.

솔잎멀칭이 근권토양 환경에 미치는 영향 솔잎 멀 칭포장과 비멀칭 포장의 블루베리 재배지 근권토양을 채취 토양 $\mathrm{pH}$ 및 유기물 함량 등을 비교분석한 결과는 Table 5 와 같다, 무주 및 옥천지역 노지재배포장에서의 솔잎멀칭포장 과 성남 및 화성지역 비멀칭포장과의 토양 $\mathrm{pH}$ 를 비교분석 한 결과 각 지역 공히 $\mathrm{pH}$ 개선, 유기물증진, 토양보습 효과 가 인정 되었다. 무주지역의 솔잎멀칭포장의 $\mathrm{pH}$ 가 4.52 인 데 비해, 비멀칭포장은 4.96 로서 지역내 차이가 크지는 않 았지만 성남 및 화성지역의 무멀칭포장과 비교할 경우 차이 가 컸다. 솔잎멀칭과 비멀칭포장과의 유기물 함량 차이는

Table 4. The effect of organic materials on the growth and development of bluebeny.

\begin{tabular}{|c|c|c|c|c|c|c|}
\hline \multirow{2}{*}{ Materials } & \multicolumn{3}{|c|}{ New Stem Size $(\mathrm{mm})$} & \multicolumn{3}{|c|}{ New Leaf Size(cm) } \\
\hline & May & September & extension & May & September & extension \\
\hline Sulfur powder & $2.6^{\mathrm{d}}$ & $5.8^{\mathrm{e}}$ & $3.2^{\text {cd }}$ & $13.5^{\mathrm{f}}$ & $51.8^{\mathrm{e}}$ & $38.3^{\mathrm{c}}$ \\
\hline Degradable sulfur granules + bentonite & $3.1^{\mathrm{a}}$ & $7.7^{\mathrm{a}}$ & $4.5^{\mathrm{a}}$ & $18.7^{\mathrm{c}}$ & $74.1^{\mathrm{b}}$ & $50.4^{\mathrm{b}}$ \\
\hline Organic acid + vinegar & $2.8^{\mathrm{c}}$ & $6.1^{\mathrm{d}}$ & $3.5^{\mathrm{bc}}$ & $20.2^{\mathrm{b}}$ & $57.2^{\mathrm{d}}$ & $37.0^{\mathrm{c}}$ \\
\hline Peat moss + Chaff + Pine Needles & $3.0^{\mathrm{b}}$ & $6.9^{\mathrm{b}}$ & $3.9^{\mathrm{b}}$ & $17.8^{\mathrm{d}}$ & $66.7^{\mathrm{c}}$ & $48.9^{\mathrm{b}}$ \\
\hline Temperature response Elutioner (CRF) & $2.5^{\mathrm{e}}$ & $6.7^{\mathrm{c}}$ & $4.9^{\mathrm{a}}$ & $22.0^{\mathrm{a}}$ & $76.5^{\mathrm{a}}$ & $57.5^{\mathrm{a}}$ \\
\hline Control & $2.5^{\mathrm{e}}$ & $5.2^{\mathrm{f}}$ & $2.7^{\mathrm{d}}$ & $13.8^{\mathrm{e}}$ & $42.4^{\mathrm{f}}$ & $28.6^{\mathrm{d}}$ \\
\hline
\end{tabular}

Table 5. The effect on weed suppression by soil mulching with pineneedles.

\begin{tabular}{clcc}
\hline \hline Mulching or non-mulching & \multicolumn{1}{c}{ Weed variety } & D.W & Control value (\%) \\
\hline Pine needles Mulching & D. sanguinalis, Portulacaceae etc. & $1.7 / \mathrm{m}^{2}$ & 98.1 \\
& D.sanguinalis, Portulacaceae Erigeronannuus, Cyperus alternifolius & \\
Non-Mulching & $\begin{array}{l}\text { Chenopodiaceae, Artemisia princeps Shepherd`s purse, Commelina } \\
\text { communis Persicaria longiseta, Ixeridium dentatum A. wilkesiana etc. }\end{array}$ & $85.0 / \mathrm{m}^{2}$ \\
\hline
\end{tabular}


크지 않았지만 토양 수분함량은 차이가 뚜렸 하였으며, 모 든 멀칭구에서 잡초억제외 부수적 효과로서 보수성. 통기성 등 토양보습 효과는 양호한 것으로 나타났다. 옥천지역은 솔잎멀칭포장의 $\mathrm{pH}$ 가 1지역은 5.14, 2지역은 3.77로 동지역 비멀칭 포장의 경우 6.42 로서 큰 차이를 나타냈다. 유기물 함량은 무멀칭포장이 $3.71 \%$ 인데 비해 멀칭포장은 4.79 10\% 로서 차이가 컸으며 토양수분도 무멀칭 $45.5 \%$ 에 비해 멀칭 포장은 57 64. 6 를 나타내 차이가 컸다. 그러나 성남 및 화 성지역의 무멀칭포장은 $\mathrm{pH}$ 4.98 6.34로 높았고 토양수분 도 33.6 59.0\%로서 적었으며, 유기물함량은 1군데를 제외 하고는 비교적 높았다.

하우스재배시 솔잎멀칭효과 블루베리 하우스 친환경 재배시 솔잎멀칭효과를 규명하기 위하여 동일포장내 무멀 칭포장과 비교한 결과는 Table 6과 같다. 토양표면 보습효 과는 큰 차이를 보이지 않았으나 토양 $\mathrm{pH}$ 및 유기물 증진효 과는 현저한 차이를 나타 내었다. 논산지역의 경우 무멀칭 하우스포장의 $\mathrm{pH}$ 가 5.34인데 비해 솔잎멀칭 하우스포장은 3.62 이고, 유기물함량은 무멀칭 $8.24 \%$ 에 비해 $12.28 \%$ 이고, 토양수분함량도 무멀칭 54.5 에 비해 멀칭은 $67.2 \%$ 로서 차 이가 컸다. 예산지역의 경우 솔잎멀칭은 $\mathrm{pH}$ 가 4.14 로서 무 멀칭 5.20과 차이를 보였고, 유기물함량은 무멀칭 $10.37 \%$ 에 비해 솔잎멀칭은 $12.47 \%$ 이었으나 수분함량은 차이가 크지
않았다. 그 밖에 유효인산함량 및 $\mathrm{CEC}$ 등 토양화학성도 상 당한 차이를 보여 블루베리 하우스재배시에도 솔잎멀칭효 과가 우수한 것으로 나타났다. 따라서 블루베리 친환경재배 시 식재 골 사이를 친환경 부직포로 피복하고 블루베리 나 무주변을 솔잎멀칭할 경우 토양 $\mathrm{pH}$ 교정, 잡초억제 및 보습 효과 등 여러 장점이 있어 블루베리 토양표면관리를 위한 효과적인 멀칭재배 수단으로 판단된다.

\section{Conclusions}

블루베리는 산성을 좋아하는 과수로 토양 $\mathrm{pH}$ 가 4.2 5.2 범위, 유기물함량 $4 \%$ 이상인 양질사토에서 잘 자라며, 적정 산도보다 토양산도가 높을 경우 생육이 부진하다. 그러나 국내 블루베리 재배토양은 유기물 함량과 토양 $\mathrm{pH}$ 조건이 블루베리를 재배하는데 부적합한 토양이 많으므로 이를 개 선하기 위하여 식재 1년 6개월전 유황분말을 뿌려 주고 식 재시 피트모스를 $50: 50$ 으로 흙과 섞어 심도록 권장하고 있다 (농촌진흥청 블루베리교본, 2009). 식재후 토양표면 관리방법으로 재배농가들은 바크, 톱밥, 짚 등 유기물을 주 로 멀칭 하였으나, 근래 솔잎을 멀칭하고 있는 농가가 늘어 나고 있으나, 그 효과에 대한 영농활용자료가 적어 자재선 택에 애로를 느끼고 있다. 이에 본 연구에서는 솔잎멀칭이 블루베리 근권토양 환경에 미치는 영향과 유기자재에 의한

Table 6. The effect on soil pH by pineneedles mulching of blueberry Field (2012 13).

\begin{tabular}{llccc}
\hline \hline Sampling area & Pine Needles mulching or non-mulching & $\mathrm{pH}(1: 5, \mathrm{w} / \mathrm{w})$ & $\mathrm{OM}(\%)$ & moisture $(\%)$ \\
\hline \multirow{2}{*}{ Muju } & Pine Needles mulching & $4.52^{\mathrm{cd}}$ & $4.15^{\mathrm{c}}$ & $60.2^{\mathrm{b}}$ \\
& non-mulching & $4.96^{\mathrm{bc}}$ & $3.87^{\mathrm{c}}$ & $47.6^{\mathrm{de}}$ \\
\hline \multirow{3}{*}{ Oukcheon } & Pine Needles mulching 1 & $5.14^{\mathrm{bc}}$ & $4.79^{\mathrm{c}}$ & $64.6^{\mathrm{a}}$ \\
& Pine Needles mulching 2 & $3.77^{\mathrm{d}}$ & $10.01^{\mathrm{a}}$ & $57.2^{\mathrm{b}}$ \\
& non-mulching & $6.42^{\mathrm{a}}$ & $3.71^{\mathrm{c}}$ & $45.5^{\mathrm{e}}$ \\
\hline \multirow{2}{*}{ Seongnam } & non-mulching 1 & $5.62^{\mathrm{abc}}$ & $8.05^{\mathrm{b}}$ & $49.8^{\mathrm{d}}$ \\
& non-mulching 2 & $6.34^{\mathrm{a}}$ & $3.87^{\mathrm{c}}$ & $33.6^{\mathrm{f}}$ \\
\hline \multirow{2}{*}{ Hwasong } & non-mulching 1 & $4.98^{\mathrm{bc}}$ & $7.50^{\mathrm{b}}$ & $59.0^{\mathrm{b}}$ \\
& non-mulching 2 & $5.75^{\mathrm{ab}}$ & $5.35^{\mathrm{c}}$ & $53.7^{\mathrm{c}}$ \\
\hline
\end{tabular}

Table 7. The effect on soil pH by pineneedles mulching of blueberry greenhouse (2013).

\begin{tabular}{|c|c|c|c|c|c|c|c|c|c|}
\hline $\begin{array}{l}\text { Sampling } \\
\text { area }\end{array}$ & $\begin{array}{l}\text { Pine Needles } \\
\text { mulching or } \\
\text { non-mulching }\end{array}$ & $\begin{array}{c}\mathrm{pH} \\
(1: 5, \mathrm{w} / \mathrm{w})\end{array}$ & $\begin{array}{l}\mathrm{OM} \\
(\%)\end{array}$ & $\begin{array}{c}\mathrm{P}_{2} \mathrm{O}_{5} \\
\mathrm{mg} / \mathrm{kg}\end{array}$ & ------- & --om & $-) / \mathrm{kg}$ & ---------- & $\begin{array}{c}\text { moisture } \\
(\%)\end{array}$ \\
\hline \multirow[t]{2}{*}{ Nonsan } & $\begin{array}{c}\text { Pine Needles } \\
\text { mulching }\end{array}$ & $3.62^{\mathrm{b}}$ & $12.28^{\mathrm{a}}$ & $650.96^{\mathrm{a}}$ & $0.38^{\mathrm{c}}$ & $3.58^{\mathrm{d}}$ & $1.39^{\mathrm{c}}$ & $30.88^{\mathrm{a}}$ & $67.2^{\mathrm{a}}$ \\
\hline & non-mulching & $5.34^{\mathrm{a}}$ & $8.14^{b}$ & $581.4^{\mathrm{c}}$ & $0.37^{\mathrm{d}}$ & $12.06^{\mathrm{a}}$ & $3.26^{\mathrm{a}}$ & $23.42^{\mathrm{b}}$ & $54.5^{\mathrm{c}}$ \\
\hline \multirow[t]{2}{*}{ Yesan } & $\begin{array}{c}\text { Pine Needles } \\
\text { mulching }\end{array}$ & $4.14^{\mathrm{b}}$ & $12.47^{\mathrm{a}}$ & $610.9^{b}$ & $0.46^{\mathrm{b}}$ & $4.10^{\mathrm{b}}$ & $1.36^{\mathrm{d}}$ & $16.49^{\mathrm{c}}$ & $56.6^{\mathrm{b}}$ \\
\hline & non-mulching & $5.20^{\mathrm{a}}$ & $10.37^{\mathrm{a}}$ & $560.2^{\mathrm{d}}$ & $0.48^{\mathrm{a}}$ & $4.02^{\mathrm{c}}$ & $2.64^{\mathrm{b}}$ & $12.34^{\mathrm{d}}$ & $48.1^{\mathrm{d}}$ \\
\hline
\end{tabular}


$\mathrm{pH}$ 교정 효과 등을 검토하여 효율적인 자재를 선발 하여 블 루베리 친환경재배시 적용하고자 본 연구를 수행하였다. 재 배시험포장의 시험전 토양 $\mathrm{pH}$ 는 6.2 이었으나 4 개월후 교 정효과는 이분해성 과립유황 4.1 , 피트모스+왕겨+솔잎 4.5 , 유기산+목초액 4.7, 유황 분말 4.8, 온도반응용출형 유황혼 합비료 5.2 순이었고, 폿트시험 에서도 유사한 경향을 보여 처리구 공히 산도교정 효과가 인정 되었다. 또한 유기물 함 량은 노지포장에서는 시험전 토양은 $5.9 \%$ 이었으나 피트모 스+왕겨+솔잎이 $8.4 \%$ 로 가장 높았고 이분해성 과립유황 $7.8 \%$, 유기산+목초액 $7.2 \%$ 순 이었다. 폿트시험에서는 유기자재 별 경향치는 포장시험 결과와 비슷하였으나 용토의 유기물 함량이 높아 무처리구의 유기물함량이 각각 $12.5 \sim 13.0$ 으로 노지포장에 비해 2 배 이상 높아 증진효과를 비교하기 어려 있는데 그 이유는 용기식재시 피트모스를 과다 투입한 포장 에서 시험한 결과라고 추정된다. 산도교정 효과에 대한 선 연구결과를 보면 유황을 이용하여 벼 육묘용 상토의 산도 조정 (kim et al., 1990) 및 피트모스 단용구가 $\mathrm{pH} 4.3$, 피트 +펄라이트 $\mathrm{pH} 4.7$ 이었다는 블루베리 삽목용토 혼합성분 분석결과 (kim et al., 2011), 그리고 알칼리성 토양 산도 교 정을 위해 완충곡선법을 이용한 황 시용량 결정 (Lee et al., 2000) 등의 결과와 비교해 볼 때 유황,유기산, 피트모스의 교정효과는 이미 알려진 효과와 비슷한 경향치를 보였으나 그밖에 유기자재에 대한 연구결과는 거의 없어 비교하기가 어려웠다. 그 외 노지 및 폿트시험포장의 토양수분 분석결 과 각 처리별로 51 66\% 범위로서 각 시험구 모두 적정수분 범위에 속하였다. 유기자재 시용에 의한 블루베리 신초생육 효과는 온도반응용출 유황혼합비료가 가장 높았으며, 이분 해성 과립유황합제, 피트모스+왕겨+솔잎, 유황분말, 유기산 + 목초액 순이었다. 한편 솔잎멀칭이 $\mathrm{pH}$, 유기물 함량 등 근 권토양 환경에 미치는 영향은 무주 및 옥천지역 솔잎멀칭포 장과 성남 및 화성지역 비멀칭 포장과의 토양 $\mathrm{pH}$ 등을 노지 포장에서 비교분석한 결과 각 지역 모두 $\mathrm{pH}$ 개선, 토양보습 효과 차이가 인정 되었으나, 솔잎멀칭과 비멀칭포장과의 유 기물 함량 차이는 크지 않았으며, 모든 솔잎멀칭구에서 잡 초억제효과가 $98 \%$ 로서 뚜렷하게 나타났다. 블루베리 하우 스재배시 동일포장내 무멀칭구와 솔잎멀칭구를 비교한 결 과 토양 $\mathrm{pH}$ 및 유기물 증진효과는 현저한 차이를 나타 내 솔잎멀칭효과를 인정할 수 있었다. 따라서 블루베리 친환경 재배시 이분해성 과립유황합제, 피트모스+왕겨+솔잎, 유황 분말, 유기산+목초액이 산도교정을 위한 유기자재로서 활 용이 가능하다고 생각되며, 또한 식재 골 사이를 친환경 부 직포로 피복하고 블루베리 나무주변을 솔잎멀칭할 경우 토 양 $\mathrm{pH}$ 교정, 잡초억제 및 보습효과 등 여러 장점이 있어 블 루베리 토양표면관리를 위한 효과적인 멀칭재배 수단으로 판단된다.

\section{References}

Alam, S.M., S.S.M. Naqvi, and R. Ansari. 1999. Impact of soil $\mathrm{pH}$ on nutrient uptake by crop plants. In Handbook of Plant and crop stress. pp. 51-60.

Austin, M.E. 1994. Potentials of blueberry production in Northeast Asia. Horticulture in Northeast Asia. J. Kor. Soc. Hort. Sci. 35(Suppl.):22-32.

Modaihsh, A.S., W.A. Al-Mustafa, and A.I. Metwally. 1989. Effect of elemental sulphur on chemical changes and untreint availability in calcaerous soils. Plant amd Soil 116:95-101.

Brown, J.C. and A.D. Draper. 1980. Differential response of blueberry (Vaccinium) progenies to $\mathrm{pH}$ and subsequent use of iron. J. Am. Soc. Hortic. Sci. 105:20-24.

Blueberry News Letter. 2011. Blueberry News. No.13:2-3. Korea Blueberry Association, Suwon, Korea.

Coville, F.V. 1910. Experiments in blueberry culture. USDA Bull. 193.

Evants, C.E. and E.J. Kamprath. 1970. Lime nesponse as related to percent $\mathrm{Al}$ saturation, solution $\mathrm{Al}$ and organic matter content, Soil Sci. Soc, Am. Proc. 34:893-896.

Gough, R.E. 1994. The highbush blueberry and its management. Food Products Press, New York, USA, Chapter 1.

Hanson, E. and J. Hancock. 1996. Managing the nutrition of highbush blueberries, Michigan State University. Extension Bulletin E-2011.

Haynes, R.J. and R.S. Swift. 1985. Effects of soil acidification on the chemical extractability of Fe, Mn, $\mathrm{Zn}$ and $\mathrm{Cu}$ and their uptake by highbush blueberry plants. Plant and Soil. 84:201-212.

Kang, J.Y., N.S. Park, H.H. Lee, and H.G. Kim. 2004. Determination of water retention characteristics of organic and inorganic substrates for horticulture by european standard method. K. J. Soil Sci. Fert. 37:55-58.

Kim, J.G., M.S. Kim, S.M. Ryou, S.M. Jung, and Y.S. Hwang. 2010. Effects of Cluster and Flower Thinning on Yield and Fruit Quality in Highbush 'Jersey' Blueberry, K.J. Bio-En. Sci. Control, 19:392-396.

Kim, E.J., K.D. Choi, and H.G. Kim. 2007. Effects of Cutting Season and Medium on the Rooting of Highbush Blueberry (Vaccinium corymbosum L.), Kor. J. Hort. Sci. Technol. 25:112-112.

Kim, H.L., H.D. Kim, J.G. Kim, Y.B. Kwack, and Y.H. Choi. 2010. Effect of Organic Substrates Mixture Ratio on 2-year-old Highbush Blueberry Growth and Soil Chemical Properties, K. J. Soil Sci. Fert. 43:858-863.

Kim, H.L., H.D. Kim, J.G. Kim, Y.B. Kwack, and Y.H. Choi. 2011. Effect of Different Soil Water Potentials on Growth Properties of Northern-Highbush Blueberry, K. J. Soil Sci. Fert. 44:161-167.

Kim, H.L., J.H. Lim, B.K. Sohn, and Y.J. Kim. 2003. Chemical properties of cut-flower rose-growing soils in plastic film houses. K. J. Soil Sci. Fert. 36:113-118. 
Korcak, R.F. 1989. Variation in nutrient requirements of blueberries and other Calcifuges. Hort Science. 24:573-578.

Lee, J.G. and B.Y. Lee. 2009. Effect of Rooting Promoter and Root Zone Temperature Controls on Growth and Rooting of Highbush Blueberry Cuttings Kor. J. Hort. Sci. Technol. 27(1):7-11.

Lindemann, W.C., J.J. Aburto. W.M. Haffner, and A.A. Bono. 1991. Effect of sulfur source on sulfur oxidation. Soil Soc. Am. J. 55:85-90.

Opala, P.A., J.R. Okalebo, and C.O. Othieno. 2012. Effects of Organic and Inorganic Materials on Soil Acidity and Phosphorus Availability in a Soil Incubation Study, ISRN Agronomy
Volume, Article ID 597216, 10.

Park, J.M., I.B. Lee, Y.I. Kang, and K.S. Hwang. 2009. Effects of Mineral and Organic Fertilizations on Yield of Hot Pepper and Changes in Chemical Properties of Upland Soil. Kor. J. Hort. Sci. Technol. 27(1):24-29.

RDA. 2000. Methods of analysis of soil and plant. National Institute of Agricultural Science and Technology, Rural Development Administration, Korea.

Sellappan, S., C.C. Akoh, and G. Krewer. 2002. Phenolic compounds and antioxidant capacity of Georgia-grown blueberries and blackberries. J. Agric. Food Chem. 50:2432-2438. 